\title{
Occurrence of Atrazine and Related Compounds in Sediments of Upper Great Lakes
}

Jiehong Guo, ${ }^{\dagger}$ Zhuona Li, $^{\dagger}$ Prabha Ranasinghe, ${ }^{\dagger}$ Solidea Bonina, ${ }^{\ddagger}, \#$ Soheil Hosseini, ${ }^{\ddagger}$ Margaret B. Corcoran, ${ }^{\S}, \#$ Colin Smalley, ${ }^{\S}$ Rajashankar Kaliappan, ${ }^{\dagger}$ Yan Wu, , Da Chen, " Andy L. Sandy, Yawei Wang, ${ }^{\perp}$ Karl J. Rockne, ${ }^{\ddagger}$ Neil C. Sturchio, ${ }^{\S, \bigcirc}$ John P. Giesy, ${ }^{\mathbb{I}}$ and An Li*, ${ }^{\dagger}$

${ }^{\dagger}$ School of Public Health, University of Illinois at Chicago, Chicago, Illinois 60612, United States

${ }^{\ddagger}$ Department of Civil and Materials Engineering, University of Illinois at Chicago, Chicago, Illinois 60607, United States

${ }^{\S}$ Department of Earth and Environmental Sciences, University of Illinois at Chicago, Chicago, Illinois 60607, United States

"Cooperative Wildlife Research Laboratory and Department of Zoology, Southern Illinois University, Carbondale, Illinois 62901, United States

${ }^{\perp}$ State Key Laboratory of Environmental Chemistry and Ecotoxicology, Research Center for Eco-Environmental Sciences, Chinese Academy of Sciences, Beijing 100085, China

${ }^{\text {II } D e p a r t m e n t ~ o f ~ V e t e r i n a r y ~ B i o m e d i c a l ~ S c i e n c e s ~ a n d ~ T o x i c o l o g y ~ C e n t r e, ~ U n i v e r s i t y ~ o f ~ S a s k a t c h e w a n, ~ S a s k a t o o n, ~ S a s k a t c h e w a n ~ S 7 N ~}$ 5B3, Canada

\section{Supporting Information}

ABSTRACT: Surface grab and core sediment samples were collected from Lakes Michigan, Superior, and Huron from 2010 to 2012, and concentrations of herbicides atrazine, simazine, and alachlor, as well as desethylatrazine (DEA), were determined. Concentrations of atrazine in surface grabs ranged from 0.01 to 1.7 $\mathrm{ng} / \mathrm{g}$ dry weight and are significantly higher in the southern basin of Lake Michigan (latitude $<44^{\circ}$ ) than other parts of the three lakes. The highest concentration of alachlor was found in sediments of Saginaw Bay in Lake Huron. The inventory and net fluxes of these herbicides were found to decline exponentially from the south to the north. The concentration ratio of DEA to atrazine (DEA/ATZ) increased with latitude, suggesting degradation of atrazine to DEA during atmospheric transport. DEA/ATZ also increased with sediment depth in the sediment cores. Diffusion of deposited herbicides from the upper sediment into deeper sediments has occurred, on the basis of the observed patterns of concentrations in dated sediment cores. Concentrations of atrazine in pore water were estimated and were higher than those reported for the bulk waters, suggesting the occurrence of solid-phase deposition of atrazine through the water column and that contaminated sediments act as a source releasing atrazine to the overlying water.

\section{INTRODUCTION}

Current agricultural practices often involve extensive use of herbicides. ${ }^{1}$ Atrazine [1-chloro-3-ethylamino-5-isopropylamino2,4,6-triazine], simazine [6-chloro- $N, N^{\prime}$-diethyl-1,3,5-triazine2,4-diamine], and alachlor [2-chloro-2,6-diethyl- $N$ (methoxymethyl)acetanilide] are among those used in the United States. Atrazine and simazine are both triazines and were initially registered as herbicides in 1958 and 1956, respectively. ${ }^{2,3}$ Alachlor, a chloroacetanilide, was first registered in 1969. ${ }^{4}$ From 1992 to 2011, reported annual usages on crops were 32000-36000 tons for atrazine, 1814-2722 tons for simazine, and 454-22 680 tons for alachlor. ${ }^{5}$ These herbicides are primarily used in the "Corn Belt" near the Great Lakes of North America, including the states of Iowa, Illinois, and Indiana and parts of others. ${ }^{1,5}$ Their use has been banned by

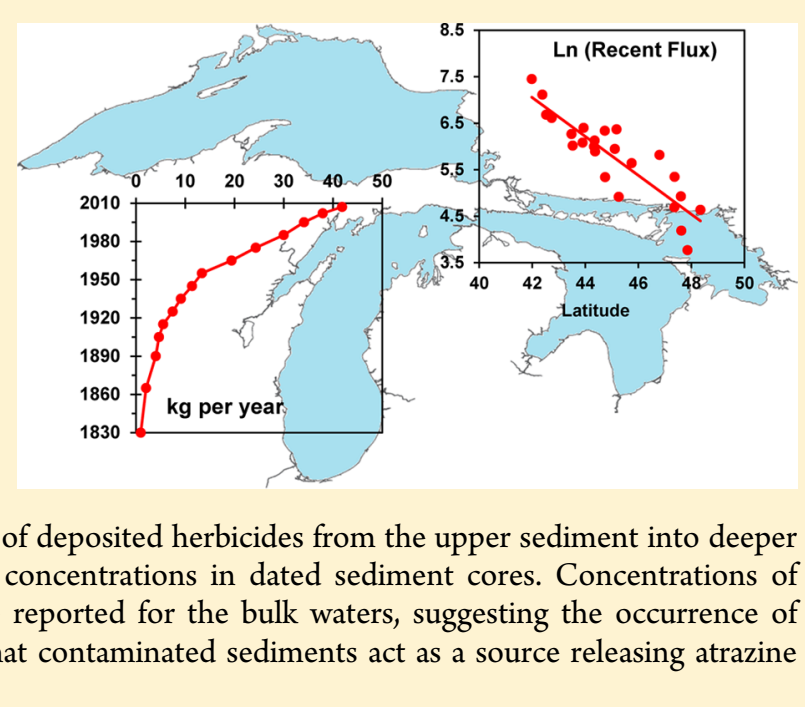

the European Union because of ubiquitous and unpreventable water contamination. Atrazine is classified as a Restricted Use Pesticide in the United States. ${ }^{6}$ According to the U.S. Environmental Protection Agency (EPA), atrazine is an endocrine disruptor, ${ }^{6}$ simazine may have reproductive or developmental toxicity, ${ }^{7}$ and alachlor was classified as a "likely" human carcinogen at high dose. ${ }^{4}$

Compared with organochlorine pesticides, atrazine and related compounds are more soluble in water. A major concern is their potential to leach from soils to surface and ground

Received: February 13, 2016

Revised: June 11, 2016

Accepted: June 20, 2016

Published: June 20, 2016 
waters that are used as sources of drinking water; ${ }^{3}$ thus, most monitoring efforts to date have been conducted for water. Atrazine was found in waters of all five Laurentian Great Lakes. $^{8-10}$ In rivers of the Midwestern U.S., elevated concentrations of atrazine, simazine, and alachlor were found during runoff events following applications. ${ }^{11-15}$ Atrazine is considered to be persistent in water, with a half-life of $>200$ days. ${ }^{16}$ In the environment, atrazine and some other triazines can degrade to desethylatrazine (DEA) and desisopropylatrazine (DIA); DIA and DEA can further degrade to desethyldesisopropyl-atrazine (DDA), and all of them could also be hydroxylated. ${ }^{17,18}$ DEA and DIA were detected in the water of Lake Michigan. ${ }^{2}$ In addition, atrazine, DEA, and DIA have been detected in air, including the vapor phase, particulate phase, and precipitation, of the Great Lakes region., ${ }^{2,19}$ Chemical structures and environmentally important physicochemical properties of atrazine and related compounds are summarized in Table S1.

In contrast to research on water and air, reports on the presence of atrazine and related compounds in sediment are limited. In rural ponds of Ontario, Canada, atrazine was found in sediment with concentrations as high as $6.4 \mathrm{mg} / \mathrm{kg}$ (compared with $17 \mu \mathrm{g} / \mathrm{L}$ in water) after accidental spills of atrazine during 1971 to $1985 .^{20}$ Atrazine, DEA, DIA, simazine, or alachlor were detected in sediments of an agricultural drainage ditch in the Mississippi Delta, ${ }^{21}$ wetlands of Texas, New Mexico, and Oklahoma, ${ }^{22}$ a small eutrophic lake in Switzerland, ${ }^{23}$ managed realignment sites in England, ${ }^{24}$ the German Bight in the North Sea, ${ }^{25}$ Ebro delta of Tarragona in Spain, ${ }^{26}$ coastal lagoon of Northern Adriatic in Italy, ${ }^{27}$ and Songhua River Basin in northeastern China. ${ }^{28}$ However, reports on herbicides in the sediments of the Great Lakes are notably sparse or nonexistent.

The objectives of this study were to investigate the spatial distribution, total mass accumulation, and temporal trends and to examine influencing factors, of atrazine, simazine, and alachlor as well as atrazine degradation product DEA in sediments of Lakes Michigan, Superior, and Huron. Additionally, concentrations of these compounds in sediment pore water were estimated and compared with previously reported concentrations in the bulk water of the lakes. To our knowledge, this is the first report on these herbicides in sediments of the Great Lakes and among only a few such reports in North America.

\section{EXPERIMENTAL SECTION}

Sampling. Surface and core sediments were collected from the U.S. EPA Research Vessel (R/V) Lake Guardian. Most samples from Lake Michigan were collected in September, 2010; additional samples from Lake Michigan (4 sampling sites) and all samples from Lake Superior were collected in June, 2011. Samples from Lake Huron including Georgian Bay and the North Channel were collected in 2012. Sampling locations are shown in Figure S1, with detailed information provided in Table $S 2$.

Grab samples of surface sediments were collected using a Ponar sampler. Each Ponar grab (PG) sample was homogenized using a paint mixer driven by an electric drill. Most sediment cores were collected by an Ocean Instrument MC400 multicorer (San Diego, California). Cores from sites M024, M032, M047, and M050 were collected by use of a box corer, and those from M008, M009, M011, and M018 were collected using an Ekman dredge corer.
At each site, four cores (10 cm in diameter) were obtained and sectioned using hydraulic extruders. All cores from Lake Michigan were sectioned into $1 \mathrm{~cm}$ intervals to a depth of 10 $\mathrm{cm}$ and then $2 \mathrm{~cm}$ intervals to a depth of $30 \mathrm{~cm}$ or the end. All cores from Lake Superior and two cores from Lake Huron (H038 and H061) were sectioned into $0.5 \mathrm{~cm}$ segments to a depth of $5 \mathrm{~cm}$ and then $1 \mathrm{~cm}$ segments to $15 \mathrm{~cm}$ depth, followed by $2 \mathrm{~cm}$ segments to 25 or $27 \mathrm{~cm}$. The other cores from Lake Huron were sectioned into $1 \mathrm{~cm}$ intervals to a depth of $15 \mathrm{~cm}$, followed by $2 \mathrm{~cm}$ intervals to a depth of $35 \mathrm{~cm}$ or the end of the cores. Different sectioning depths were selected on the basis of predicted sedimentation rates at different sites for best possible resolution of deposition chronology. To minimize potential "smearing", sediment within $2 \mathrm{~mm}$ of the wall of the coring tube was trimmed off and discarded. After each segment was cut, all sectioning gear was thoroughly cleaned using tap water, acetone, and deionized water. At each site, the segments at corresponding depths were combined and mixed using stainless steel spoons in glass bowls.

Well-mixed samples of Ponar grab and composite core segments were distributed into precleaned $125 \mathrm{~mL}$ amber glass jars with Teflon-liner screw caps and immediately frozen. Samples were transported to the laboratory in coolers, where they were stored at $-20{ }^{\circ} \mathrm{C}$ until further processing and analyses to determine the concentrations of targeted chemicals in this laboratory and selected radionuclides in a collaborating laboratory. Another portion was refrigerated in a $50 \mathrm{~mL}$ Falcon tube.

Sediment Characterization and Core Dating. From the $50 \mathrm{~mL}$ Falcon tube, triplicate subsamples were taken with a 3 $\mathrm{mL}$ syringe barrel and weighed before and after drying to constant mass, and the bulk and dry density, particle density, water and solids contents were determined by use of standard methods. ${ }^{29,30}$ Dried subsamples were combusted at $375{ }^{\circ} \mathrm{C}$ for $24 \mathrm{~h}$, and loss of mass was termed "organic matter". Total carbon was measured using the procedures previously described. ${ }^{31-33}$ Samples used for determination of total organic carbon were acidified by slow addition of $10 \% \mathrm{HCl}$ to excess (at least $10 \mathrm{~mL}$ of $\mathrm{HCl}$ per g dry mass of sediment) and shaken for $24 \mathrm{~h}$ to remove all forms of carbonate. ${ }^{33}$ Residual acid was removed using at least three cycles of vortex mixing with deionized water, centrifugation, and removal of supernatant. The $\mathrm{pH}$ was measured to ensure all residual acid was removed. Acidified and washed samples were then dried, and total organic carbon was measured as above for total carbon.

Samples of cores in $125 \mathrm{~mL}$ jars were lyophilized and a $\sim 3 \mathrm{~g}$ aliquot of each homogenized core section was used for dating. Activities of radionuclides ${ }^{210} \mathrm{~Pb}$ and ${ }^{137} \mathrm{Cs}$ were measured by gamma spectrometry using HPGe well detectors (Ortec) interfaced with DSPEC-Plus digital signal processors, from gamma emissions at 46.5 and $661.6 \mathrm{keV}$, respectively. Detector efficiencies were calibrated against standard reference materials DL-1a (CANMET U-Th ore) for U- and Th-series radionuclides and NIST-4365 (ocean sediment) for ${ }^{137} \mathrm{Cs}$ in sample geometry. Peak areas were corrected for background, and errors were estimated from counting statistics. The mass sedimentation rate (MSR) and focusing factor (FF) obtained from cumulative excess ${ }^{210} \mathrm{~Pb}$ inventories are presented in Table S2. The year of deposition for core segments was estimated using the MSR and dry mass of collected sediment. Cores collected at sites H037, S001, and S114 could not be dated due to low sediment accumulation (Table S2). 
Identification and Quantification of Analytes. A standard mixture of herbicides and pesticides (Catalog \# M525.2-CP-ASL) was purchased from AccuStandard (New Haven, CT). Individual standards of atrazine, DEA, DIA, and DDA were also purchased from AccuStandard. Surrogate deuterated benzo[e]pyrene (BeP-d12) and tributyl phosphate (TBP-d27) and internal standards deuterated fluorene (FLUd10) and ${ }^{13} \mathrm{C}$ labeled $2,4,2^{\prime}, 4^{\prime}$-tetrachlorobiphenyl (PCB47L) were purchased from Cambridge Isotope Laboratories, Inc. (Tewksbury, MA). All solvents were HPLC or Optima grade and purchased from Fisher Scientific (Pittsburgh, PA). Silica gel (100-200 mesh, 75-150 $\mu \mathrm{m}$, grade 644), alumina (neutral, Brockmann I, 50-200 $\mu \mathrm{m}$ by Acros Organics), and granular anhydrous sodium sulfate $\left(\mathrm{Na}_{2} \mathrm{SO}_{4}\right)$ were also obtained from Fisher Scientific. Alumina and $\mathrm{Na}_{2} \mathrm{SO}_{4}$ were activated at $500{ }^{\circ} \mathrm{C}$ for $8 \mathrm{~h}$, and silica gel was activated at $160{ }^{\circ} \mathrm{C}$ for at least $16 \mathrm{~h}$ or $500{ }^{\circ} \mathrm{C}$ for $8 \mathrm{~h}$. They were stored at $160^{\circ} \mathrm{C}$ and cooled to room temperature in desiccators before use.

A detailed description of laboratory procedures has been published elsewhere. ${ }^{34}$ In brief, approximately $5 \mathrm{~g}$ of freezedried sediment of each sample was extracted with an accelerated solvent extraction system (Dionex ASE350, Thermo Fisher Scientific, Inc.). The sediment was extracted for three cycles using a hexane and acetone $(1: 1, \mathrm{v} / \mathrm{v})$ mixture at $100{ }^{\circ} \mathrm{C}$ with heating time of $5 \mathrm{~min}$ and static time of $10 \mathrm{~min}$ in each cycle. The extract was concentrated in a rotary evaporator and solvent-exchanged into hexane. A glass column $(11 \mathrm{~mm}$ id $\times 40 \mathrm{~cm}$ long) was prefilled with dichloromethane (DCM). Then, the column was filled from bottom to top with $1 \mathrm{~g}$ of granular anhydrous $\mathrm{Na}_{2} \mathrm{SO}_{4}, 8 \mathrm{~g}$ of alumina, $4 \mathrm{~g}$ of silica gel, and $4 \mathrm{~g}$ of granular anhydrous $\mathrm{Na}_{2} \mathrm{SO}_{4}$. After the column was packed, DCM was completely replaced by hexane. Concentrated extract was added to the prepared columns and eluted with $100 \mathrm{~mL}$ of hexane (F-1), $100 \mathrm{~mL}$ of $4: 1$ hexane/ DCM (v/v) mixture (F-2), $100 \mathrm{~mL}$ of DCM (F-3), and 100 $\mathrm{mL}$ of methanol (F-4). The target analytes of this work were in F-3 and F-4, which were solvent exchanged into hexane. Surrogates BeP-d12 and TBP-d27 were eluted in F-3 and F-4, respectively, along with the target analytes. ${ }^{34}$ Aliquots of both fractions were placed in a $200 \mu \mathrm{L}$ glass insert of a $2 \mathrm{~mL}$ vial for instrumental analysis.

An Agilent 7890 gas chromatograph (GC) coupled with an Agilent 7000 triple quadrupole mass spectrometer (QQQ-MS) was used to identify and quantify targeted analytes. The multimode injection port was operated in solvent vent mode with $60 \mu \mathrm{L}(20 \mu \mathrm{L} \times 3)$ of total injection per run. The inlet temperature started at $0{ }^{\circ} \mathrm{C}$, which was held for $2.1 \mathrm{~min}$, and then increased to $300{ }^{\circ} \mathrm{C}$ at $600{ }^{\circ} \mathrm{C} / \mathrm{min}$. The vent flow was $300 \mathrm{~mL} / \mathrm{min}$. The purge flow was $60 \mathrm{~mL} / \mathrm{min}$ at a run time of 3 $\mathrm{min}$. The carrier gas was helium, and the flow was kept constant at $1.2 \mathrm{~mL} / \mathrm{min}$. A Restek RXi-XLB capillary column $(30 \mathrm{~m} \times$ $0.25 \mathrm{~mm}$ i.d. $\times 0.10 \mu \mathrm{m}$ film thickness) was used for separation. The initial oven temperature was set at $50{ }^{\circ} \mathrm{C}$, which was held for $3 \mathrm{~min}$, then increased to $100{ }^{\circ} \mathrm{C}$ at $10{ }^{\circ} \mathrm{C} / \mathrm{min}$, then increased to $300{ }^{\circ} \mathrm{C}$ at $5{ }^{\circ} \mathrm{C} / \mathrm{min}$, and kept for $5 \mathrm{~min}$ until the run was completed. The GC-MS interface was kept at $300{ }^{\circ} \mathrm{C}$. Temperature of the electron impact (EI) ion source was set at $230{ }^{\circ} \mathrm{C}$, and temperatures of both quadrupole 1 and quadrupole 2 were set at $150{ }^{\circ} \mathrm{C}$. Data were acquired in multiple reactions monitoring (MRM) mode. Transition ions of the target analytes, surrogates, and internal standards are summarized in Table S3a, and example total ion chromatograms are provided in Figure S2a. Atrazine, simazine, and alachlor were analyzed in all the samples. DEA was analyzed in all Ponar grab samples, four cores (M011, M018, M032, and M041) of Lake Michigan, and all cores in Lakes Superior and Huron.

To ensure correct identification of analytes, the extracts of Ponar grab sediment from site M044 and core from M018 were solvent-exchanged into methanol and filtered through nylon 0.2 $\mu \mathrm{m}, 500 \mu \mathrm{L}$ centrifugal filters (VWR, Radnor, PA), then analyzed by an Agilent 1260 HPLC (Agilent Technologies, Santa Clara, CA), and interfaced with a 3200 Q Trap triple quadrupole/linear ion trap mass spectrometer ( $A B$ Sciex; Toronto, Canada) for atrazine, DEA, DIA, and DDA. The ion transitions used for identification and quantification are given in Table S3b. The LC mobile phase A was $0.1 \%$ formic acid water solution, and $\mathrm{B}$ was $0.1 \%$ formic acid methanol solution. The flow rate was $200 \mu \mathrm{L} / \mathrm{min}$. The initial mobile phase was $95 \%$ A (5\% B). It was decreased to $80 \%$ in $2 \mathrm{~min}$ and held until $5 \mathrm{~min}$, then decreased to $50 \%$ in $5 \mathrm{~min}$, further decreased to $20 \%$ in another $5 \mathrm{~min}$, and finally to $5 \%$ in $2 \mathrm{~min}$ and held for $2 \mathrm{~min}$. Sample chromatograms are shown in Figure S2b. The comparison between GC and HPLC analyses revealed relatively large uncertainties in the analyses of DIA; therefore, data for DIA are not discussed further in this paper, although it was found in most samples.

Quality Control. Two laboratory procedural blanks $\left(\mathrm{Na}_{2} \mathrm{SO}_{4}\right)$ were processed along with sediment samples of each core, and four blanks were prepared for Ponar grab samples in each lake. Concentrations of target compounds in the blanks ranged from below detection limit (N.D.) to $0.1 \mathrm{ng} /$ g dry weight $(\mathrm{dw})$. Surrogates BeP-d12 (8 ng) and TBP-d27 (8 ng) were added to each sample before extraction, and their respective average recovery \pm standard deviation (S.D.) was $103 \pm 21 \%$ and $93 \pm 28 \%(N=500)$, respectively. A number of samples were re-extracted or the extracts were reinjected into GC/MS in order to meet the quality control criteria that the recoveries of both surrogates must be between $60 \%$ and $135 \%$. The concentrations are reported in this paper without adjustment based on surrogate recoveries. One sample from each core and two samples of the Ponar grabs in each lake were analyzed in duplicate. The average relative percentage differences (RPDs) for atrazine, simazine, alachlor, and DEA are 17 $\pm 26 \%(N=35), 10 \pm 10 \%(N=10), 26 \pm 36 \%(N=35)$, and $15 \pm 17 \%(N=31)$, respectively. In addition, duplicate blanks $\left(\mathrm{Na}_{2} \mathrm{SO}_{4}\right)$ were spiked with the target analytes $(8-20 \mathrm{ng}$ each) and the average recoveries were $89 \pm 9 \%$ for atrazine, $74 \pm 26 \%$ for DEA, $123 \pm 5 \%$ for simazine, and $129 \pm 18 \%$ for alachlor. The detection limits based on three times of signal-to-noise ratio were $0.020 \mathrm{ng} / \mathrm{g}$ for atrazine, $0.22 \mathrm{ng} / \mathrm{g}$ for DEA, $4.32 \mathrm{ng} /$ $\mathrm{g}$ for DDA, $0.024 \mathrm{ng} / \mathrm{g}$ for simazine, and $0.003 \mathrm{ng} / \mathrm{g}$ for alachlor, with the use of $5 \mathrm{~g}$ of sediment.

Estimation of Net Deposition Flux, Inventory, and Total Accumulation. Laboratory data for sediment cores were used to estimate the following: ${ }^{35}$

$$
\text { net deposition flux }{ }_{\mathrm{i}}\left(\mathrm{ng} \mathrm{m}^{-2} \mathrm{y}^{-1}\right)=C_{\mathrm{i}} \times \mathrm{MSR} / \mathrm{FF} \times 10^{4}
$$

inventory $\left(\mathrm{ng} \mathrm{cm}^{-2}\right)=\sum C_{\mathrm{i}} \rho_{\mathrm{b}, \mathrm{i}} d_{\mathrm{i}}$

annual loading rate $\left(\mathrm{kg} \mathrm{y}^{-1}\right)$

$$
=\text { average flux } \times \text { lake water surface area } \times 10^{-6}
$$


Table 1. Median (Range) Concentrations (ng/g dw) ${ }^{a}$ and Detection Rates (\%) of Atrazine, DEA, Simazine, and Alachlor in Sediment Samples from Lakes Michigan, Superior, and Huron

\begin{tabular}{|c|c|c|c|c|c|}
\hline lake & $N$ & atrazine & DEA & simazine & alachlor \\
\hline \multicolumn{6}{|c|}{ Ponar Grab } \\
\hline Michigan & 29 & $0.67(0.06-1.74) 100 \%$ & $0.68(0.11-1.39) 97 \%$ & $0.43(0.01-1.42) 79 \%$ & $0.02(0.001-0.085) 76 \%$ \\
\hline Superior & 24 & $0.09(0.01-1.73) 63 \%$ & $0.11(0.11-0.72) 17 \%$ & $0.01(0.01-2.67) 21 \%$ & $0.001(0.001-0.077) 4 \%$ \\
\hline Huron & 59 & $0.15(0.01-0.74) 66 \%$ & $0.61(0.11-0.96) 68 \%$ & $0 \%$ & $0.001(0.001-0.43) 17 \%$ \\
\hline \multicolumn{6}{|c|}{ Core Surface } \\
\hline Michigan & $9^{b}$ & $4.94(2.53-6.18) 100 \%$ & $2.46(1.25-2.77) 100 \%$ & $1.39(0.01-1.91) 89 \%$ & $0.18(0.06-0.33) 100 \%$ \\
\hline Superior & 9 & $1.15(0.10-1.66) 100 \%$ & $0.89(0.11-1.51) 89 \%$ & $0 \%$ & $0.05(0.001-0.12) 78 \%$ \\
\hline Huron & 9 & $2.67(1.26-3.28) 100 \%$ & $1.63(0.76-2.80) 100 \%$ & $0 \%$ & $0.14(0.05-0.28) 100 \%$ \\
\hline
\end{tabular}
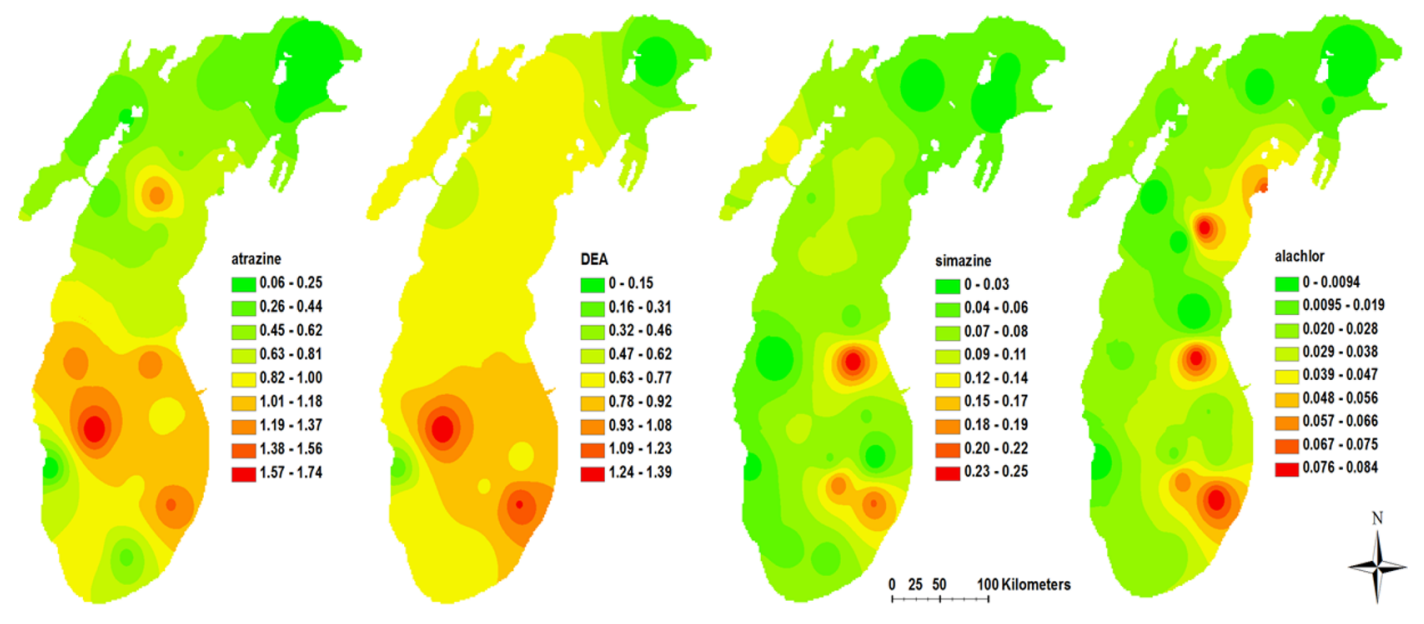

Figure 1. Inverse distance weighted interpretation of spatial distribution of target herbicides in surface sediment of Lake Michigan (Unit: ng/g dw).

total load $(\mathrm{kg})=$ average inventory $\times$ lake water surface area $\times 10^{-2}$

where $C_{\mathrm{i}}$ is the chemical concentration $\left(\mathrm{ng} \mathrm{g}^{-1} \mathrm{dw}\right), \rho_{\mathrm{b}, \mathrm{i}}$ is the dry mass bulk density $\left(\mathrm{g} \mathrm{cm}^{-3}\right)$, and $d_{\mathrm{i}}$ is the thickness $(\mathrm{cm})$ of segment i. The MSR is in $\mathrm{g} \mathrm{cm}^{-2} \mathrm{y}^{-1}$, and the FF is dimensionless (Table S2). The water surface areas of Lakes Michigan, Superior, and Huron are 57 800, 82 100, and 59600 $\mathrm{km}^{2}$, respectively. Other constants are for unit conversions. The "average" used in eqs 3 and 4 was either the mean of cores or the average inverse distance weighted interpretation results from spatial analysis of ArcGIS 10 based on cores.

\section{RESULTS AND DISCUSSION}

Spatial Variation. Table 1 summarizes the medians and ranges of measured concentrations in both Ponar grab samples and the surface segments $(0-1$ or $0-0.5 \mathrm{~cm})$ of sediment cores. Data obtained for individual coring stations are presented in Table S4. Concentrations in the top segments of cores are in general higher than those in Ponar grabs at the same location. This was expected because the Ponar sampler penetrated to depths exceeding $10 \mathrm{~cm}$, where the sediment is generally less contaminated (see below). The concentrations of atrazine are about 2-20 times higher than those predicted from water data in the 1990s for Lakes Michigan (0.072 ng/g), Superior (0.005 $\mathrm{ng} / \mathrm{g})$, and Huron $(0.063 \mathrm{ng} / \mathrm{g}){ }^{36}$ Consistent with the geographic pattern of agricultural uses, ${ }^{5}$ concentrations of atrazine in the sediment are in the rank order of Lake Michigan $>$ Lake Huron > Lake Superior. This is in general agreement with the north to south increasing pattern of atrazine concentration in water of the Great Lakes. ${ }^{9}$ Table S5 summarizes the results from other sediment studies for comparison purposes.

Spatial variations in concentration within individual lakes are illustrated in Figure 1 for Lake Michigan and Figure S3 for Lakes Superior and Huron, on the basis of the results of Ponar grab samples. In Figure S4 and Table S6, the data are further compared among eight geographic regions of the study area. On the basis of Fisher's exact test, concentrations of both atrazine and simazine were significantly higher in southern Lake Michigan than in other regions including northern Lake Michigan (Table S6). From the core data (Table S4), the highest recent net flux of atrazine was observed at M008 and M009 near the mouths of the heavily contaminated Grant, St. Joseph, and Kalamazoo Rivers, ${ }^{2}$ indicating significant impact of riverine inputs to southern Lake Michigan. Site M050 in Green Bay had significantly lower concentrations of atrazine than all sites in the main lake. A similar south-north comparison for Lake Michigan was reported for atrazine in the particulate phase of air. ${ }^{2}$ These observations are consistent with the larger agricultural land coverage, as well as higher concentrations of atrazine in tributaries, in the southern drainage basin compared to the northern basin of Lake Michigan. ${ }^{2}$ In Lake Superior, the concentration of atrazine was higher in the western than in the eastern part of the lake (Figure S4 and Table S6). In Lake Huron, the differences in atrazine and simazine concentrations among northern and southern main lakes as well as the North Channel and Georgian Bay were found to be statistically insignificant.

Concentrations of alachlor were lower than those of other herbicides investigated. Agricultural use of alachlor has decreased significantly since $1994 .{ }^{5}$ In the Corn Belt, alachlor 

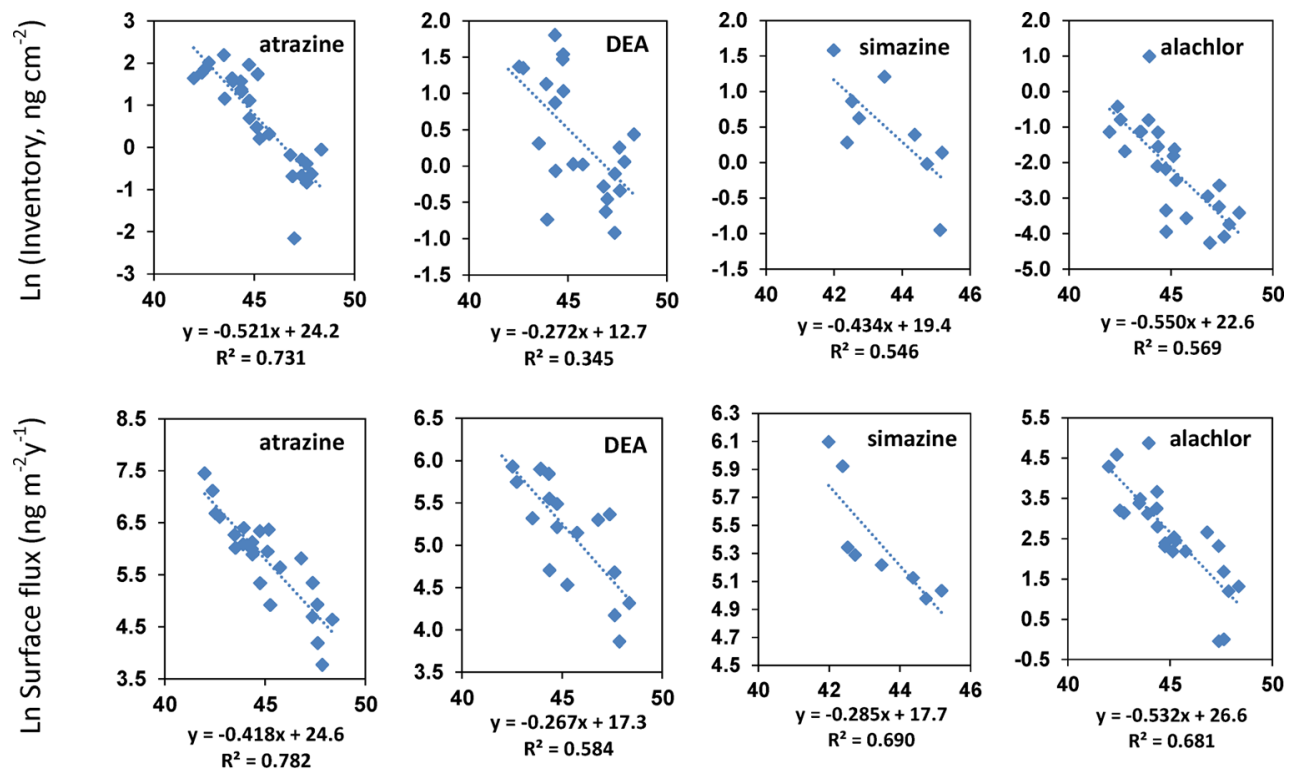

\section{Latitude}

Figure 2. Dependence of inventory and surface flux on the latitude of the sampling locations for selected herbicides. The plots for simazine use data from Lake Michigan only. All regressions are significant at 95\% confidence level.

in wet deposition was less than that of atrazine and tended to fall closer to the agricultural field where it was applied. ${ }^{1}$ In addition, alachlor in water was found to be rapidly transformed to 2-[(2,6-diethylphenyl)-(methoxymethyl)amino]-2-oxoethanesulfonate (ESA). ${ }^{14}$ In contrast to the other herbicides in this study, there was no statistically significant difference in alachlor concentrations between the southern and northern basins $(p=0.436)$ of Lake Michigan, which may be due in part to the relatively high concentrations near the Sleeping Bear Dunes (sites M093a-c) in the northern basin (Figure 1). In Lake Superior, alachlor was found in only one Ponar grab sample collected at S011. In Lake Huron, alachlor was found in $17 \%$ of samples with the highest concentration $(0.43 \mathrm{ng} / \mathrm{g})$ at site $\mathrm{H} 001$ in Saginaw Bay, indicating local uses. The correlations between concentrations of alachlor and those of atrazine and DEA are comparatively weak (Table S7), consistent with the different use histories between alachor and atrazine.

Over the entire study area across the three lakes, the inventory and net fluxes of these herbicides were found to decline exponentially with the increasing latitude of the sampling sites (Figure 2). Evidence of long-range transport of atrazine over at least $500 \mathrm{~km}$ has been reported from analyzing rainwater and air. ${ }^{37}$ The observations in this work provide further evidence using sediment data. The empirical "halfdistance" is the distance over which the net surface flux and inventory in the sediment is reduced by $50 \%$. It was estimated by the use of eq 5 below, which assumes first order decline with increasing distance.

$$
d_{1 / 2}(\mathrm{~km})=-\ln 2 / \text { slope } \times 111.2
$$

where slopes of regressions are presented in Figure 2 and 111.2 $\mathrm{km}$ per degree latitude was used for unit conversion. For atrazine, $d_{1 / 2}$ was approximately $150 \pm 18 \mathrm{~km}$ for the inventory and $180 \pm 21 \mathrm{~km}$ for the recent depositional flux, with the uncertainties calculated from the relative standard errors of the slopes.
DEA/Atrazine Ratio. Degradation product DEA was detected in most Ponar grab samples from Lakes Michigan and Huron, and the concentrations are similar between the two lakes (Table 1). DEA was found at only four sampling sites (S002, S108, S116, and S119) in Lake Superior. The dependence on the latitude is weaker for DEA than for the herbicides discussed above (Figure 2), and its empirical halfdistance is much longer at about $280 \pm 90 \mathrm{~km}$ for the inventory and $290 \pm 60 \mathrm{~km}$ for the recent depositional flux. The degradation of DEA may lead to the formation of DDA; ${ }^{17}$ however, DDA was found in only a few of the samples at the relatively high detection limit.

The DEA to atrazine concentration ratio (DEA/ATZ) has often been used as an indicator of atrazine degradation. ${ }^{15,18,19,38}$ Low DEA/ATZ ratios, e.g., <0.1, occur in streams during runoff shortly after application of atrazine. The ratio increases after considerable degradation of atrazine to DEA has occurred in soil. $^{1}$ A comparatively large ratio $(\sim 0.5)$ of DEA/ATZ in rainfall suggests degradation of atrazine in the atmosphere. ${ }^{1}$ For Lake Michigan, the median DEA/ATZ was 0.68 (range of $0.43-1.04$ ) in the open lake water and 0.77 (range of 0.083.7) in waters of tributaries during 1994 and 1995 . $^{2}$ In air above Lake Michigan, DEA/ATZ in precipitation and particulates averaged 0.52 and 0.25 , respectively. ${ }^{2}$ In this study, the median DEA/ATZ ratio was 0.42 (range of $0.30-0.47$ ) in surface sediment samples from Lake Michigan. Furthermore, the ratio increased with increasing latitude of the sampling sites over the entire study area (Figure 3), suggesting that transformation of atrazine to DEA occurred while transporting northwards.

In most cores in which DEA was measured, a pattern of increasing DEA/ATZ ratio with increasing sediment depth was observed (Figure 4). The ratio of $0.3-1$ observed at core surfaces tends to be constant to a particular depth and then increases to as high as 6 in deeper sediments. This could be an indication of transformation of atrazine to DEA in deeper sediments; however, it may also be caused by possibly more rapid downward diffusion of DEA due to its greater water 


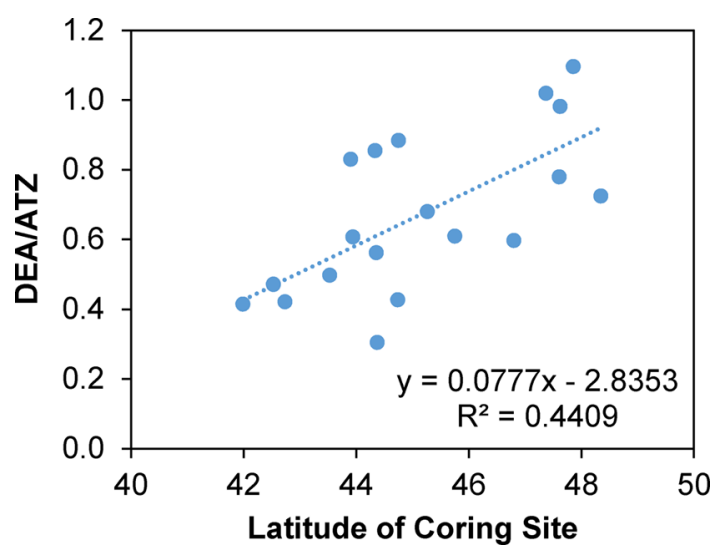

Figure 3. Variation in concentration ratio of DEA over atrazine (DEA/ ATZ) with latitude in core surface sediment samples of Lakes Michigan, Superior, and Huron $(p=0.002)$.

\section{Ratio (DEA/ATZ)}

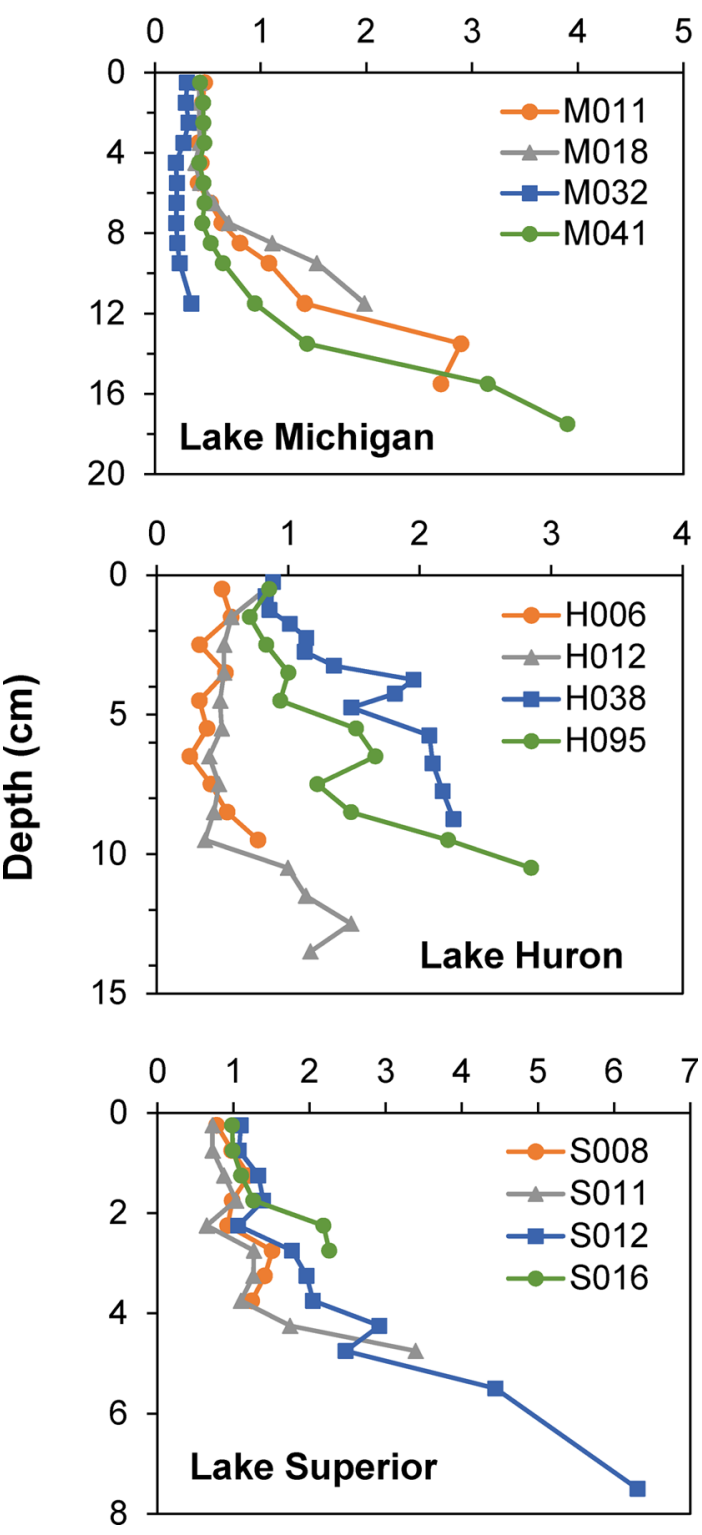

Figure 4. Variation in concentration ratio of DEA over atrazine (DEA/ ATZ) with depth in selected sediment cores. solubility relative to atrazine (Table S1). The latter explanation is consistent with a previous report that atrazine rapidly biodegraded in incubated surface ( $<10 \mathrm{~cm}$ depth) sediment but not under anaerobic or denitrifying conditions in sediment from $20 \mathrm{~cm}$ depth in a southern Lake Ontario basin. ${ }^{38}$ A similar observation was reported comparing the surface versus subsurface sediments collected from an agricultural farm. ${ }^{39}$ Atrazine was also found to be least persistent in top soil, and its persistence increased with increasing soil depth. ${ }^{40}$ A study on triazines in the water of a number of ombrotrophic lakes in Isle Royale suggests faster degradation and shorter half-lives in shallower lakes. ${ }^{19}$ Removal of the ethyl and isopropyl side chains, which leads to formation of DEA and DIA, respectively, is considered to be an aerobic process. ${ }^{41}$

Vertical Trends. Net deposition fluxes are plotted against deposition year for the four Lake Michigan coring sites in Figure 5. With the exception of alachlor, the trends in the sediments are consistent with a first order pseudokinetics increase in more recent years. For atrazine, the average apparent doubling times $\left(t_{2}\right)$ are 33,48 , and 62 years in the sediments of Lakes Michigan, Superior, and Huron, respectively (Table S8). However, a closer examination of data found that, in most cases, target chemicals were detected in sediments deposited before the year 1900 (Figure 5). This emergence date is much earlier than the initial production date. In addition, the annual use of atrazine has leveled off or declined since the early $1990 \mathrm{~s},{ }^{5}$ but the net deposition to sediment appears to be continuously increasing. Together, these results suggest the occurrence of vertical transport of the chemicals from upper sediment layers to deeper sediment layers. With relatively high water solubilities and low solid phase partitioning constants (Table S1), it is likely that the target compounds would have been diffusing through the sediment pore water in response to the concentration gradient, causing significant downward transport within sediment over decadal time scales.

To test this possibility, we estimated analyte concentrations in pore water, $C_{w}$, assuming equilibrium with the sediment in situ using the measured solid phase concentration as follows:

$$
C_{\mathrm{W}}(\mathrm{ng} / \mathrm{L})=\frac{1000 \times \mathrm{C}_{\mathrm{s}}}{f_{\mathrm{oc}} \times K_{\mathrm{oc}}+\frac{f_{\mathrm{w}}}{\left(1-f_{\mathrm{w}}\right) \times \rho}}
$$

where $\mathrm{C}_{\mathrm{s}}(\mathrm{ng} / \mathrm{g} \mathrm{dw})$ is the measured concentration in dried sediment, $f_{\text {oc }}$ (dimensionless) is the measured organic carbon (OC) fraction of the sediment, $K_{\mathrm{oc}}(\mathrm{L} / \mathrm{kg})$ is the OC-water partition coefficient (Table S1), $f_{\mathrm{w}}$ (dimensionless) is the measured mass fraction of water in sediment, and $\rho$ is water density, $1 \mathrm{~kg} / \mathrm{L}$. Estimated concentrations in pore water of Ponar grab sediments of Lake Michigan have medians of 111, 161, 90, and $5 \mathrm{ng} / \mathrm{L}$ for atrazine, DEA, simazine, and alachlor, respectively. These correspond to approximately 39\%, 65\%, $53 \%$, and $46 \%$ of the measured total (pore water + particle) mass for the four chemicals, respectively. In the absence of advection (either upward or downward), such high percentages in pore water of the upper sediment layers would result in a strong concentration gradient and thus were likely to have caused downward diffusion into deeper sediment layers, consistent with what was observed (Figure 5).

Sediment as Source to the Water Column. While diffusion from upper to lower layers in the sediment has likely been occurring, the herbicides found in the upper sediment may not result from diffusion from the overlaying water at most 


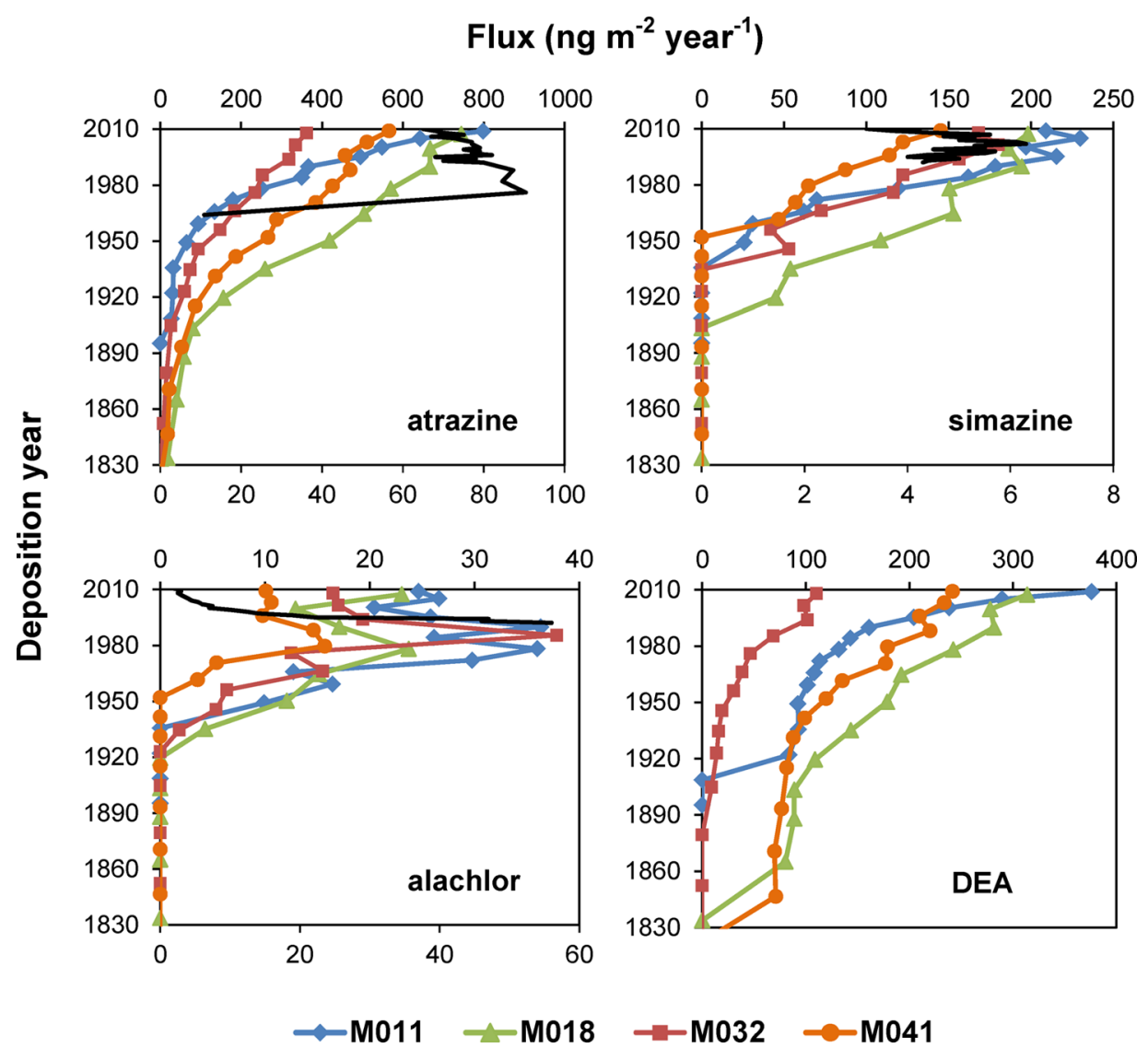

Figure 5. Apparent deposition flux of selected herbicides to the sediment at four locations of Lake Michigan, estimated using eq 1 . The black lines (lower $x$-axis) are the annual crop uses of the three herbicides in million lbs. ${ }^{5}$

Table 2. Recent Annual Loading and Total Load ( \pm Standard Deviation), Calculated from the Mean Concentrations in Sediment Cores Using eqs 3 and $4^{a}$

\begin{tabular}{|c|c|c|c|c|}
\hline lake & atrazine & DEA & simazine & alachlor \\
\hline \multicolumn{5}{|c|}{ Recent Annual Loading to Sediment, $\mathrm{kg} \mathrm{y}^{-1}$} \\
\hline Michigan & $44.4 \pm 25.6$ & $11.3 \pm 14.1$ & $12.1 \pm 7.5$ & $1.9 \pm 1.8$ \\
\hline Superior & $11.8 \pm 7.6$ & $8.3 \pm 6.0$ & NA & $0.4 \pm 0.4$ \\
\hline Huron & $21.9 \pm 8.4$ & $14.8 \pm 5.7$ & NA & $2.1 \pm 2.2$ \\
\hline Total & $78.0 \pm 75.1$ & $34.3 \pm 33.3$ & $12.1 \pm 7.5$ & $4.5 \pm 6.2$ \\
\hline \multicolumn{5}{|c|}{ Total Load in Sediment, $\mathrm{kg}$} \\
\hline Michigan & $3329 \pm 1234$ & $1184 \pm 904$ & $1140 \pm 796$ & $169 \pm 99$ \\
\hline Superior & $484 \pm 191$ & $713 \pm 287$ & NA & $23 \pm 18$ \\
\hline Huron & $1952 \pm 843$ & $1514 \pm 1041$ & NA & $269 \pm 480$ \\
\hline Total & $5764 \pm 5083$ & $4111 \pm 3195$ & $1140 \pm 796$ & $461 \pm 1009$ \\
\hline
\end{tabular}

sampling locations. The most recently reported concentrations of atrazine had medians (minimum to maximum) of 55 (48 to 71) $\mathrm{ng} / \mathrm{L}, 13.2$ (4.7 to 32$) \mathrm{ng} / \mathrm{L}$, and 5.4 (5.1 to 6.0$) \mathrm{ng} / \mathrm{L}$ in the water of Lakes Michigan, Huron, and Superior, respectively. ${ }^{8}$ These are below the atrazine concentrations predicted by eq 6 for sediment pore waters, which had the medians of 111 (24 to 990) ng/L, 34 (not detected to 770) ng/ $\mathrm{L}$, and 14 (not detected to 260) ng/L, for Lakes Michigan, Huron, and Superior, respectively. Although the sampling dates and locations are different between the two studies, the differences suggest the occurrence of solid-phase deposition of atrazine through the water column.

Atrazine, with a $K_{\mathrm{oc}}>100$ (Table S1) and capable of donating and accepting hydrogen bonds, ${ }^{42}$ can interact with soil and sediment organic matter by multiple mechanisms. Organic content of the sediment has been found to affect sorption, transport, and degradation of atrazine in sediments. ${ }^{43-46}$ Once applied to soil in crop fields or sorbed to airborne particulate matter, atrazine may not be easily desorbed from the particles. Atrazine has a reported half-life of 45 to $60 \mathrm{~d}$ in soils of the Midwestern U.S. ${ }^{37}$ In a study of persistence of atrazine in soil using lysimeters, ring- ${ }^{14} \mathrm{C}$-labeled atrazine was still detectable 22 years after the last application. ${ }^{47}$ In another study, $13 \%$ to $43 \%$ of atrazine spiked into two sediments became unextractable after 2 years by the use of aqueous solutions containing methanol. ${ }^{48}$ We therefore propose that, upon entering lakes with river inflows or via atmospheric deposition, contaminated particles may settle to the lake bed before losing much of the 
sorbed atrazine, especially at near shore sites where the water is shallow. Once at the lake bottom, the herbicide can be released through desorption and can enter bulk water via diffusion and during sediment resuspension. Future work is needed to test these hypotheses.

On a lake-wide basis, the total loads of atrazine in water of lakes during the 1990s were estimated to be 176 tonnes for Lake Michigan, 75 tonnes for Lake Huron, and 36 tons for Lake Superior. ${ }^{49}$ Compared with the sediment loads of atrazine in the three lakes (Table 2), water is the major compartment for atrazine and organic compounds with similar physicochemical properties. However, the role played by contaminated sediment cannot be ignored. Sustained release to the water from contaminated sediments of the lake and tributaries as well as the soils in the region may be at least partially responsible for the increasing atrazine concentrations observed in Lake Michigan, even though the annual use of atrazine has leveled off or declined in the Corn Belt since the early 1990s. ${ }^{5}$ Atrazine, simazine, DEA, and DIA are among the most frequently detected contaminants in Chicago's water supply. ${ }^{50}$ Toxicity of these compounds on benthic diatoms and amphipods is also a serious concern. ${ }^{51,52}$ To this end, the findings of this work provide valuable information and insights in understanding the behavior and potential impact of these herbicides in the Great Lakes and beyond.

\section{ASSOCIATED CONTENT}

\section{(S) Supporting Information}

The Supporting Information is available free of charge on the ACS Publications website at DOI: 10.1021/acs.est.6b00706.

Tables and figures including the physicochemical properties, instrument conditions and chromatograms of target compounds, and sampling information, as well as additional results of data analyses (PDF)

\section{AUTHOR INFORMATION}

\section{Corresponding Author}

*Phone: 1-312-996-9597; fax: 1-312-413-9898; e-mail: anli@ uic.edu.

\section{Present Addresses}

${ }^{\#}$ S.B. and M.B.C.: Great Lakes National Program Office, U.S. EPA Region V, Chicago, Illinois, United States.

${ }^{\nabla}$ A.L.S.: Depart of Environmental Science, Rutgers, The State University of New Jersey, New Brunswick, New Jersey, United States.

${ }^{O}$ N.C.S.: Department of Geological Sciences, University of Delaware, Newark, Delaware, United States.

\section{Notes}

The authors declare no competing financial interest.

\section{ACKNOWLEDGMENTS}

This research was part of the Great Lakes Sediment Surveillance Program (GLSSP) funded by a Cooperative Agreement from the U.S. EPA Great Lakes Restoration Initiative with Assistance No. GL-00E00538 (EPA Program Officer Todd Nettesheim). J.G. was also supported by the Predoctoral Fellowship provided by the Institute for Environmental Science and Policy at the University of Illinois at Chicago. We thank the crew of R/V Lake Guardian for their assistance during sampling. We acknowledge the participation in the sampling cruises by Gregory Bourgon, Garry Codling, Kelly Granberg, and Felipe Tendick-Matesanz. J.P.G. was supported by the program of 2012 "High Level Foreign Experts" (\#GDT20143200016) funded by the State Administration of Foreign Experts Affairs, the P.R. China to Nanjing University, and the Einstein Professor Program of the Chinese Academy of Sciences. He was also supported by the Canada Research Chair program, a Visiting Distinguished Professorship in the Department of Biology and Chemistry, and State Key Laboratory in Marine Pollution, City University of Hong Kong.

\section{REFERENCES}

(1) Goolsby, D. A.; Thurman, E. M.; Pomes, M. L.; Meyer, M. T.; Battaglin, W. A. Herbicides and their metabolites in rainfall: Origin, transport, and deposition patterns across the midwestern and northeastern United States, 1990-1991. Environ. Sci. Technol. 1997, 31 (5), 1325-1333.

(2) Brent, R. N.; Schofield, J.; Miller, K. Results of the Lake Michigan mass balance study: Atrazine data report; US Environmental Protection Agency, Great Lakes National Program Office: Chicago, IL, 2001.

(3) Gunasekara, A. S. Environmental Fate of Simazine; Environmental Monitoring Branch, Cal/EPA Department of Pesticide Regulation: Sacramento, CA, 2004.

(4) USEPA. R.E.D. Facts for Alachlor; http://www3.epa.gov/ pesticides/chem_search/reg_actions/reregistration/fs_PC-090501_1Dec-98.pdf (Accessed 11/22/2015).

(5) USGS. Pesticide National Synthesis Project; http://water.usgs.gov/ nawqa/pnsp/usage/maps/compound listing.php (Accessed 02/05/ 2015).

(6) USEPA. Atrazine Chemical Summary; https://archive.epa.gov/ region5/teach/web/pdf/atrazine_summary.pdf (Accessed 02/18/ 2015).

(7) USEPA. Reregistration Eligibility Decision for Simazine; (EPA 738R-06-008); https://www3.epa.gov/pesticides/chem search/reg actions/reregistration/red_PC-080807_6-Apr-06.pdf (Accessed 03/ 29/2015).

(8) Kurt-Karakus, P. B.; Muir, D. C.; Bidleman, T. F.; Small, J.; Backus, S.; Dove, A. Metolachlor and atrazine in the great lakes. Environ. Sci. Technol. 2010, 44 (12), 4678-4684.

(9) Struger, J.; L'italien, S.; Sverko, E. In-use Pesticide Concentrations in Surface Waters of the Laurentian Great Lakes, 1994-2000. J. Great Lakes Res. 2004, 30 (3), 435-450.

(10) Schottler, S. P.; Eisenreich, S. J. Herbicides in the great lakes. Environ. Sci. Technol. 1994, 28 (12), 2228-2232.

(11) Battaglin, W. A.; Goolsby, D. A. Are Shifts in Herbicide Use Reflected in Concentration Changes in Midwestern Rivers? Environ. Sci. Technol. 1999, 33 (17), 2917-2925.

(12) Capel, P. D.; Larson, S. J. Effect of scale on the behavior of atrazine in surface waters. Environ. Sci. Technol. 2001, 35 (4), 648657.

(13) Tagert, M. L.; Massey, J. H.; Shaw, D. R. Water quality survey of Mississippi's Upper Pearl River. Sci. Total Environ. 2014, 481, 564573

(14) Thurman, E. M.; Goolsby, D. A.; Aga, D. S.; Pomes, M. L.; Meyer, M. T. Occurrence of Alachlor and Its Sulfonated Metabolite in Rivers and Reservoirs of the Midwestern United States: The Importance of Sulfonation in the Transport of Chloroacetanilide Herbicides. Environ. Sci. Technol. 1996, 30 (2), 569-574.

(15) Thurman, E. M.; Goolsby, D. A.; Meyer, M. T.; Mills, M. S.; Pomes, M. L.; Kolpin, D. W. A reconnaissance study of herbicides and their metabolites in surface water of the midwestern United States using immunoassay and gas chromatography/mass spectrometry. Environ. Sci. Technol. 1992, 26 (12), 2440-2447.

(16) USATSDR. Tox Guide for Atrazine; http://www.atsdr.cdc.gov/ toxguides/toxguide-153.pdf (Accessed 03/29/2015).

(17) Panshin, S. Y.; Carter, D. S.; Bayless, E. R. Analysis of Atrazine and Four Degradation Products in the Pore Water of the Vadose Zone, Central Indiana. Environ. Sci. Technol. 2000, 34 (11), 21312137. 
(18) Thurman, E. M.; Meyer, M. T.; Mills, M. S.; Zimmerman, L. R.; Perry, C. A.; Goolsby, D. A. Formation and transport of deethylatrazine and deisopropylatrazine in surface water. Environ. Sci. Technol. 1994, 28 (13), 2267-2277.

(19) Thurman, E.; Cromwell, A. E. Atmospheric transport, deposition, and fate of triazine herbicides and their metabolites in pristine areas at Isle Royale National Park. Environ. Sci. Technol. 2000, 34 (15), 3079-3085.

(20) Frank, R.; Braun, H. E.; Ripley, B. D.; Clegg, B. S. Contamination of rural ponds with pesticide, 1971-85, Ontario, Canada. Bull. Environ. Contam. Toxicol. 1990, 44 (3), 401-409.

(21) Bennett, E. R.; Moore, M. T.; Cooper, C. M.; Smith, S., Jr. Method for the simultaneous extraction and analysis of two current use pesticides, atrazine and lambda-cyhalothrin, in sediment and aquatic plants. Bull. Environ. Contam. Toxicol. 2000, 64 (6), 825-833. (22) Belden, J. B.; Hanson, B. R.; McMurry, S. T.; Smith, L. M.; Haukos, D. A. Assessment of the effects of farming and conservation programs on pesticide deposition in high plains wetlands. Environ. Sci. Technol. 2012, 46 (6), 3424-3432.

(23) Papilloud, S.; Haerdi, W.; Chiron, S.; Barceló, D. Supercritical Fluid Extraction of Atrazine and Polar Metabolites from Sediments Followed by Confirmation with LC-MS. Environ. Sci. Technol. 1996, 30 (6), 1822-1826.

(24) Kadiri, M.; Spencer, K.; Heppell, C. Potential contaminant release from agricultural soil and dredged sediment following managed realignment. J. Soils Sediments 2012, 12 (10), 1581-1592.

(25) Bester, K.; Hühnerfuss, H. Triazine herbicide concentrations in the German Wadden Sea. Chemosphere 1996, 32 (10), 1919-1928.

(26) Ferrer, I.; Hennion, M.-C.; Barceló, D. Immunosorbents coupled on-line with liquid chromatography/atmospheric pressure chemical ionization/mass spectrometry for the part per trillion level determination of pesticides in sediments and natural waters using low preconcentration volumes. Anal. Chem. 1997, 69 (22), 4508-4514.

(27) Carafa, R.; Wollgast, J.; Canuti, E.; Ligthart, J.; Dueri, S.; Hanke, G.; Eisenreich, S.; Viaroli, P.; Zaldívar, J. Seasonal variations of selected herbicides and related metabolites in water, sediment, seaweed and clams in the Sacca di Goro coastal lagoon (Northern Adriatic). Chemosphere 2007, 69 (10), 1625-1637.

(28) Sun, X.; Zhou, Q.; Wang, Y.; Ren, W. Influence of hydrogeomorphology, land-use and riparian zone characteristics on herbicide occurrence and distribution in sediments in Songhua River Basin, northeastern China. Geoderma 2013, 193-194 (0), 156-164.

(29) Rice, E. W.; Bridgewater, L.; American Public Health Association. Standard methods for the examination of water and wastewater; American Public Health Association: Washington, DC, 2012.

(30) Carter, M. R.; Gregorich, E. G. Soil sampling and methods of analysis, 2nd ed.; CRC Press: Boca Raton, FL, 2007.

(31) Buckley, D. R.; Rockne, K. J.; Li, A.; Mills, W. J. Soot deposition in the Great Lakes: Implications for semi-volatile hydrophobic organic pollutant deposition. Environ. Sci. Technol. 2004, 38 (6), 1732-1739.

(32) Verardo, D. J.; Froelich, P. N.; McIntyre, A. Determination of organic carbon and nitrogen in marine sediments using the Carlo Erba NA-1500 Analyzer. Deep-Sea Res., Part A 1990, 37 (1), 157-165.

(33) Lukasewycz, M. T.; Burkhard, L. P. Complete elimination of carbonates: A critical step in the accurate measurement of organic and black carbon in sediments. Environ. Toxicol. Chem. 2005, 24 (9), 2218-2221.

(34) Guo, J.; Li, Z.; Sandy, A. L.; Li, A. Method development for simultaneous analyses of multiple legacy and emerging organic chemicals in sediments. J. Chromatogr. A 2014, 1370, 1-8.

(35) Song, W.; Ford, J. C.; Li, A.; Mills, W. J.; Buckley, D. R.; Rockne, K. J. Polybrominated diphenyl ethers in the sediments of the Great Lakes. 1. Lake Superior. Environ. Sci. Technol. 2004, 38 (12), 3286-3293.

(36) Zhang, Q.; Crittenden, J. C.; Shonnard, D.; Mihelcic, J. R. Development and evaluation of an environmental multimedia fate model CHEMGL for the Great Lakes region. Chemosphere 2003, 50 (10), 1377-1397.
(37) Calamari, D.; Jones, K.; Kannan, K.; Lecloux, A.; Olsson, M.; Thurman, M.; Zannetti, P. Monitoring as an Indicator of Persistence and Long-Range Transport. In Evaluation of persistence and long-range transport of organic chemicals in the environment; Klecka, G., Boethling, R., Franklin, J., Grady, L., Graham, D., Howard, P. H., Kannan, K., Larson, R., Mackay, D., Muir, D., Eds.; SETAC: Pensacola, FL, 2000.

(38) Topp, E.; Gutzman, D. W.; Millette, J.; Gamble, D. S.; Bourgoin, B. Rapid mineralization of the herbicide atrazine in alluvial sediments and enrichment cultures. Environ. Toxicol. Chem. 1995, 14 (5), 743747.

(39) Radosevich, M.; Traina, S. J.; Tuovinen, O. H. Biodegradation of atrazine in surface soils and subsurface sediments collected from an agricultural research farm. Biodegradation 1996, 7 (2), 137-149.

(40) Kruger, E. L.; Somasundaram, L.; Coats, J. R.; Kanwar, R. S. Persistence and degradation of [14C]atrazine and [14C]deisopropylatrazine as affected by soil depth and moisture conditions. Environ. Toxicol. Chem. 1993, 12 (11), 1959-1967.

(41) Wolf, D. C.; Martin, J. P. Microbial Decomposition of Ring-14C Atrazine, Cyanuric Acid, and 2-Chloro-4,6-diamino-s-triazine. J. Environ. Qual. 1975, 4 (1), 134-139.

(42) Welhouse, G. J.; Bleam, W. F. Atrazine hydrogen-bonding potentials. Environ. Sci. Technol. 1993, 27 (3), 494-500.

(43) Smalling, K. L.; Aelion, C. M. Distribution of atrazine into three chemical fractions: impact of sediment depth and organic carbon content. Environ. Toxicol. Chem. 2004, 23 (5), 1164-1171.

(44) Lima, D. L.; Schneider, R. J.; Scherer, H. W.; Duarte, A. C.; Santos, E. B.; Esteves, V. I. Sorption- Desorption Behavior of Atrazine on Soils Subjected to Different Organic Long-Term Amendments. J. Agric. Food Chem. 2010, 58 (5), 3101-3106.

(45) Wu, Q.; Yang, Q.; Zhou, W.; Zhu, L. Sorption characteristics and contribution of organic matter fractions for atrazine in soil. J. Soils Sediments 2015, 15 (11), 2210-2219.

(46) Schwarzenbach, R. P.; Gschwend, P. M.; Imboden, D. M. Sorption I: General Introduction and Sorption Processes Involving Organic Matter. In Environmental Organic Chemistry; John Wiley \& Sons, Inc.: New York, 2005; pp 275-330.

(47) Jablonowski, N. D.; Koppchen, S.; Hofmann, D.; Schaffer, A.; Burauel, P. Persistence of $14 \mathrm{C}$-labeled atrazine and its residues in a field lysimeter soil after 22 years. Environ. Pollut. 2009, 157 (7), 21262131.

(48) Seybold, C. A.; Mersie, W.; McName, C.; Tierney, D. Release of Atrazine (14C) from Two Undisturbed Submerged Sediments over a Two-Year Period. J. Agric. Food Chem. 1999, 47 (5), 2156-2162.

(49) Schottler, S. P.; Eisenreich, S. J. Mass balance model to quantify atrazine sources, transformation rates, and trends in the Great Lakes. Environ. Sci. Technol. 1997, 31 (9), 2616-2625.

(50) City of Chicago Emerging Contaminant Study; http://www. cityofchicago.org/city/en/depts/water/supp_info/water_quality_ resultsandreports/city of chicago emergincontaminantstudy.html (Accessed 01/22/2016).

(51) Ralston-Hooper, K.; Hardy, J.; Hahn, L.; Ochoa-Acuña, H.; Lee, L. S.; Mollenhauer, R.; Sepúlveda, M. S. Acute and chronic toxicity of atrazine and its metabolites deethylatrazine and deisopropylatrazine on aquatic organisms. Ecotoxicology 2009, 18 (7), 899-905.

(52) PurdueNews A Great Lakes mystery: The case of the disappearing species; http://www.purdue.edu/uns/x/2008a/ 080528SepulvedaVanishing.html (Accessed 02/06/2016). 